\title{
الأنشطة الفنية والثقافية والرياضية في لواء العمارة حتى عام 1901
}

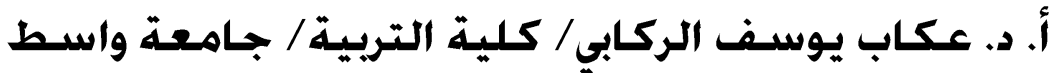

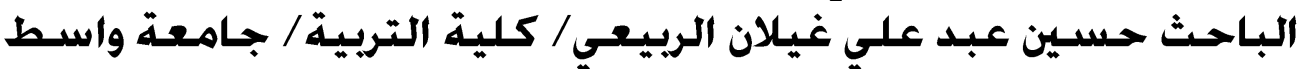 مـنم:} أن دراسة الأنشطة الفنية والثقافية والرياضية في لواء العمـارة حتى عام 90 19 1، يتطلب معرفة الظروف المحيطة في اللواء ومـا نتج عنها حيث أن حجم الإهمال الذي تعرض لله هذا اللواء وعدم الاهتمام بسكاته جعل من سكان اللواء يتحملون كافة الأعباء المتعلقة بالواقع فئع الثقافي بدءا من التعليم حتى ابسط ما يرتبط بالجوانب الفنية ثقافيا، فقد برز العطاء الفني بطاقات هائلة في أرياف ومدن اللواء واصبح الغناء

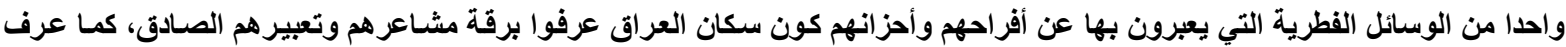
سكان اللواء التمثيل والمسرح في وقت مبكر فضلاً عن انتشار دور العرض السينمائي ومختلف أنواع الفنون الأخرى وكان للجوانب الرياضية دور مهم في تنشيط الحركة الثقافية بين السكان .

\section{Artistic, cultural and sports activities in liwa' Al-eamara till $19 \diamond \wedge$}

Prof. Dr. Akab Youssef Al-Rikabi

University of Wasit

Faculty of Education

History Department
Hussein Abdul Ali Al-Rubaiey

University of Wasit

Faculty of Education

History Department

Graduate Studies / Masters

the modern history

Abstract:

The study of Artistic, cultural and sport activities in liwa' aleamara till $190 \wedge$ needs to know the surrounding circumstances in Al- liwa and what was resulted from it like the negligence and carelessness which made its people bear all responsibilities concerning the cultural reality starting from education till the simplest artistic and cultural aspects.

The artistic tender was appeared with huge capacity in the cities and rural areas of liwa' aleamara and the singing became one of the Intuitive means in which the people explain its pleasure and sadness through it as the people of Iraq known from their tender emotion and their sincere expression. The people of Al-liwa know the representation and the theater in the early times in addition to the spread of cinemas and various types of arts, the sport aspects has an important role in activating cultural movement among the citizens.

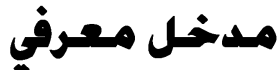

أن در اسـة الأنشـطة الفنيـة و الثقافيـة والرياضـية في لـواء العمـارة حتى عـام 901 1، يتطلب معرفـة الظروف المحيطة في اللواء وما نتج عنها، حيث أن حجم الإهمال الذي تعرض لـه هذا اللواء و عدم الاهنمام بسكانه جعل من سكان اللواء يتحملون كافة الأعباء المتعلقة بالو اقع الثقافي بدءاً من التعليم حتى ابسط مـا يرتبط بالجو انب الفنية ثقافيا، فقد برز العطاء الفني بطاقات هائلة في أرياف ومدن اللواء و واصبح الغناء واحداً من الوسائل الفطرية التي يعبرون بها عن أفر احهم وأحز انهم كون سكان العراق عرفوا برقة مشـاعرهم وتعبير هم الصادق عنه، وكان للهجة العمارية دور كبير في الغناء الريفي الذي ولد في أهوار ومنـاطق الريف في لواء العمارة وقد كان للشعر الثعبي الدور الكبير في تزويد المغنين بذلك على الرغم من تأديتهم الغناء دون اللات موسيقية ولم تكن معروفة إلا القليل منها وهي بسيطة وبذلك ظهرت أطوار عديدة للغناء الريفي.

وكان سكان اللو اء قد عرفوا المسرح منذ وقت مبكر كونه مرتبط بذكرى عاثـور اء الخالدة وفي تاريخ العراق الحديث والمعاصـر يعد لواء العمارة أسبق ألويـة العراق الأخرى في هذا المجـال حيث عرضت أول 
مسرحية في العراق عام VI9 19، وكان ذللك في قضاء قلعة صالح التابع إلى لواء العمارة، وبعد ذلك أزدهر فن التمثيل في عموم اللواء وتشكلت عدد من الجمعيات والفرق الخاصـة بالتمثيل وظهور المسرح في المدارس ورياض الأطفال في لو اء العمارة، وقد ساعد في تطور ها الزيار ات التي كانت تقوم بها عدد من الفرق الفنية من بن

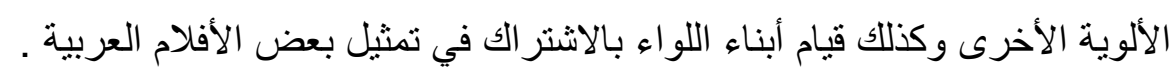
إما دور السينما فقد نشطت في مركز مدينة العمارة التي ظهرت فيها منذ عام ؟ 9 (، وكانت تابعة إلى سكان اللواء ولم تكن هنـاك أيسة جهود حكوميـة إلا مـا قرره مجلس إدارة اللواء عـام 1907 في جلب ثـلاث سينمات صغيرة توزع لمدن اللواء. وقد نشطت جو انب فنية أخرى تمثلت في مهرجانات الخط و الرسم و الأعمـال اليدويـة، وقد بـرز في اللواء فن فلكلوري خـاص وهو فن الصياغة والنفش على المعـادن الثمينـة والأحجـار الكريمة وبرز في هذا المجال صاغة اشتهروا محلياً عالمياً. وبعد التغير ات التي طر أت على العراق نشطت الحركة الرياضية وعرف السكان الكثير من الألعاب الرياضية وظهرت أهمية الحركة الكثفية وكان للواء العمارة مركز مهم في هذه الجوانب على مستوى العراق

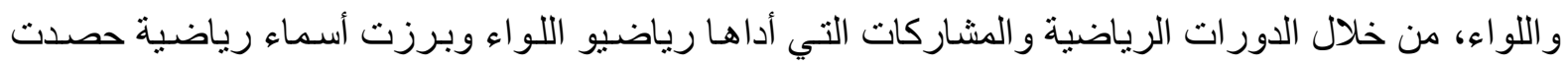
الكثير من الجوائز ووصل بعضهم لارجة الأبطال على مستوى العراق في العديد من الألعاب الرياضية .

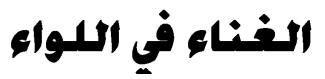

أشتهر لو اء العمارة بعطائه الفني المتميز في كافة المجالات الفنية والثقافية ورفد العراق بطاقات هائلة في هذه الجوانب جعلته يحتل مرتبة الصدارة بين ألوية العراق الأخرى ومن الملاحظ أن الظواهر الفنية تولد في مر اكز المدن ثم تتطلق نحو أطر افها، إما في لواء العمارة فنجد العكس حيث ينفرد اللواء بعملية و لادة الفنون في المناطق البعيدة عن مر اكز المدن والمتمثلة في مناطق الريف ومناطق الأهو ار ثم تتجه نحو المدن(') ويعد الغناء في مناطق أهو ار اللواء حالة إنسانية فطريـة ترتبط بالإنسـان ذاته وأتخذ منها وسيلة يعبر فيها عن مـا يخالج

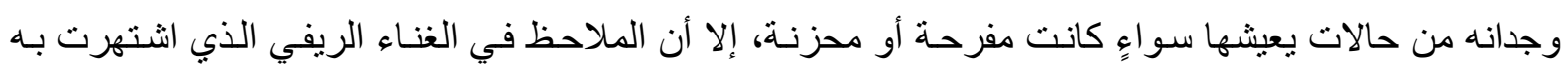
مناطق اللواء يختلط بنز عة الحزن العميق الذي يمنزج معه البكاء الذي يطغي عليه في أغلب الأحيان. وتميز سكان العر اق منـذ أقدم العصـور برقـة شـعور هم و عمق تفكير هم وقدرتهم العاليـة في وصفهر للطبيعة وما يحيط بهم وعبروا عن ذلك بما كتبوه في أطار الثعر الشعبي المحلي حسب لهجات مدن العراق(؟) وتعتبر اللهجة العمارية بمفرداتها التي لا نجدها في مدن العراق الأخرى قد هيأت المنـاخ الملائم لثـعر اء الثـعر

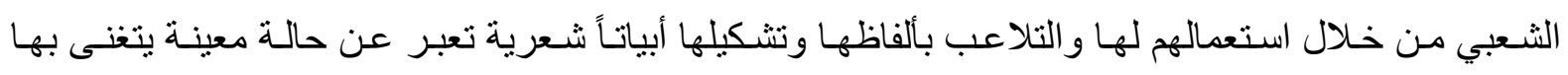

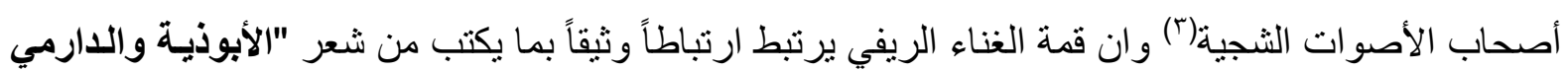

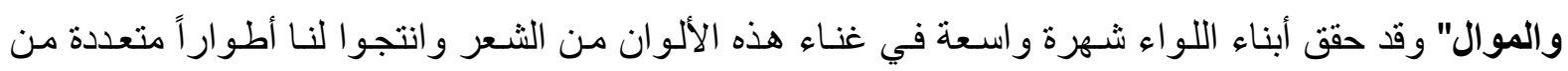
الغناء الريفي واحتلوا من حيث عدد هذه الأطوار المرتبة الأولى بين أرياف مناطق العراق و غالباً مـا تغنى دون آلات موسيقية في منـاطق الريف (؛) بينمـا نجد في منـاطق التجمعات البدويـة وجود لبعض الآلات الموسيقية

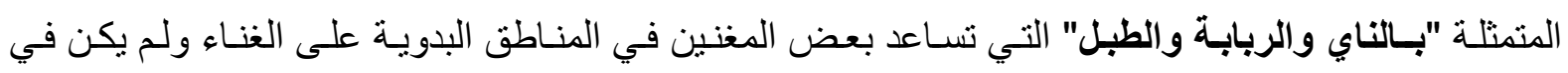


مناطق الأهو ار منها سوى الطبل المصنوع بطريقة بدائية() ومن أنثهر الأطوار التي ظهرت في لواء العمارة مثلل: "الصنداكي، السحماوي، النوري، اللآمس، السرحاني، الهـيل، المجراوي" وقد تفرع من هذه الأطوار أطوار أخرى مشتقة منها حتى أصبحت بأعداد كثيرة وأصبح كل طور منها ينسب إلى المنطقة التي ظهر فيها وعرف في ربو عها لأول مرة، وأصبح لكل طور مغنوه الخاصسون لـه و المشهورون بـه وأخذت تلك الأطوار

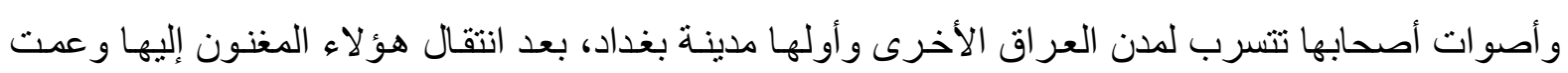
شهرتهم من خلال شركات التسجيل التي سجلت للعديد منهم(؟) ومن أنثهر المغنون الريفيون في لواء العمارة:-

1- كاطع كيطان

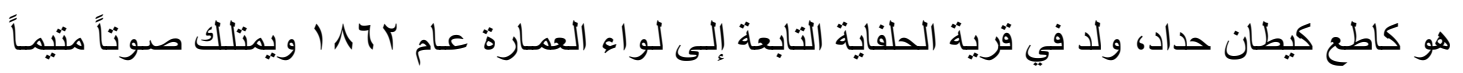
مليئاً بالثجن وفي غنائه يظهر كأنه يعبر عن معاناة البسطاء و المحملين بالهموم وكان يعمل في صيد السمك في

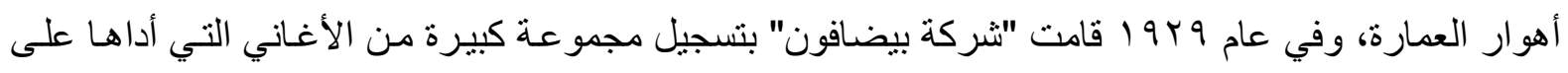
عدد من الأسطو انات وبذللك حفظ صوته من الضياع وتم توثيقه من خلالهاب(') .

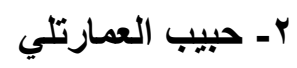

هو حبيب عبدالله مشعل، ولد في أطر اف لواء العمـارة عام 9.9 أوكان يغنسي اغلب أطوار الغنـاء العماري، وقد تمكنت شركات التسجيل من فرز صوته كأحد الأصـوات الغنائية المميزة، وسجلت لـه عدد من الأسطو انات وتم توثيق ذلك بشهادتها بعذوبة صوته و الاعتر اف له بذلكي(^) .

\section{ب- ألوس الفرطوسي}

هو ألوس فرج مكي، ولد في المجر الكبير عام 1910 وتجاوز بصوته وطريقة غنائه جميع أبناء جيله

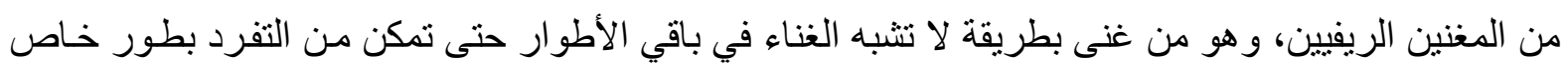
به سمي "الهديل" وبسبب نقاء صوته و عذوبته تم اختياره للغناء في فلم "(لقاهرة- بغداد" وكان فلم مشترك بين

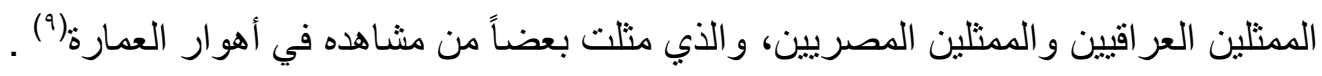
ع- سلمان المنكوب

هو سالم غلام علي شرهان من عشيرة العواشتق "البو عامر" ولد في كميت عام 1911 من عائلة

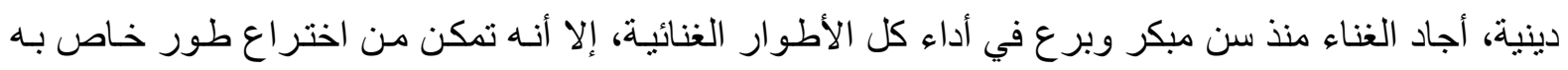
بعد أن أتقن سلمه الموسيقي بحرفية عالية وهو عازف لعدة آلات موسيقية مثنل "العود والكمـان والربابـة" ومن خلال تنقله في أكثر من عمل واحتكاكه بالأجانب العاملين في العر اق تمكن من أجادة عدة لغات مثنل "التركية، الفارسية، الإنجليزية، الألمانية، الهندية" وفي عام V 9 1)، طلبته الإذاعة اللاسلكية للغناء وبعد عام أصبح من مطربي الإذاعة وذاع صيته وسجلت له "شركة بيضافون" و "شركة جقماقجي" وكان يكتب عن الثـعر الجاهلي بالثـعر الثـعبي وكتب قصيدة مدح في "أديسـون مختـرع الكهربـاء" وقصـيدة أخرى بحـق "الززعيم الهندي

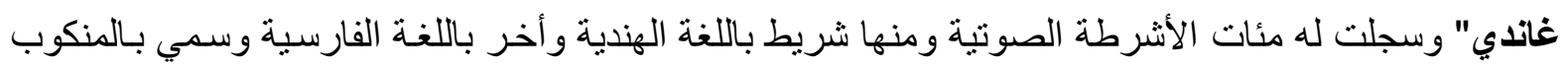
لأنه سكن منطقة المنكوبية في بغداد التي أخذت اسمها بعد غرقها بفيضان دجلة في أحد الأعوام(·ـ"( ). 


$$
\text { ه- جواد وادي }
$$

هو جو اد وادي سعدون، ولد في المشرح عام 9 وا و وبدأ الغناء في سن الثالثة عشر وبسبب التشجيع

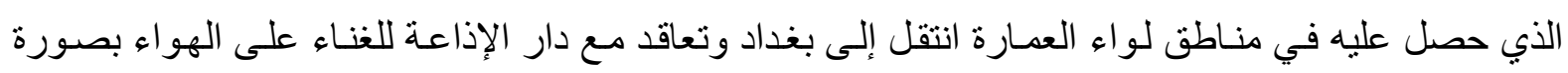

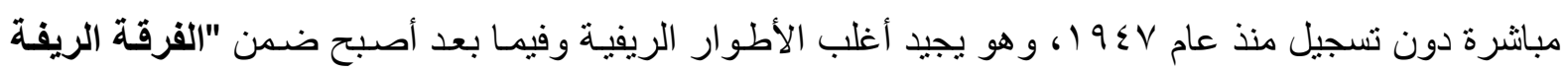
التابعة للمؤسسة العامة للإذاعة والتلفزيون" وقامت الإذاعة بتسجيل عدد كبير من الأشرطة الصونية له (') .

$$
\text { 7- حنش السرحان }
$$

هو حنش بوشي سـرحان، ولد في أهوار العمـارة عام 9 و 19 وتأثر بو الده وطريقة غنائه منذ طفولتـه حيث بدأ يقلده في الغناء ويتقن جميع الأطوار الريفية، وسجلت له العديد من الأشرطة الصسوتية عندما أنتقل إلى

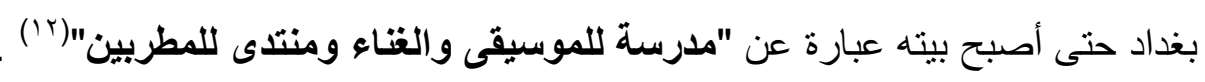

\section{ش- شويثة}

هي شويشة حسن اكعيد، ولدت في أهو ار العمارة عام . .9 19 ودخلت عالم الغناء الريفي بما تمتلك من صوت غنائي و أصبحت لها شعبية كبيرة من المعبين بصوتهاو غنائها، وتمكنت كصوت نسائي من تجاوز كل العقبات السائدة في ذلك الوقت حتى أصبحت "مطربـة الليالي ونجمـة أماسـي الطرب" وفي عام سبو 1 بدأت "شركة بيضافون" بتسجيل الكثير من الأسطو انات لها وساعدتها على أقامت الكثير من الحفلات الغنائية وهي زوجة المطرب الريفي "حريب صنكور" وخالة المطرب "عبادي العماري"(ז') . 1- مسعود العمارتلي

هي مسعودة سعد افحيص، ولدت في أهوار اللواء عام 19 أ وبسبب مـا حصل معها "سيكولوجياً" تحولت إلى طباع الرجال وسلوكهم وبدأت ترتدي ملابس الرجال منذ وقت مبكر من عمرهـا، حتى وصل بها

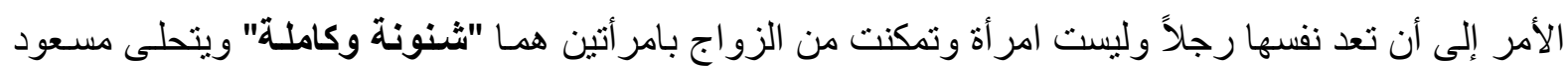
بصوتٍ عذب جعله يتميز بين الأخرين من أبناء جيله وله رصيد كبير من الأغاني، لكونهه جاد كل الألوان الغنائية وغنى في "دار الإذاعة" قبل أن تعرف الإذاعة أجهزة التسجيل وتمكنت الكثير من الثـركات المحلية

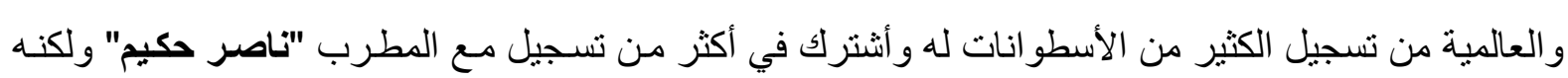

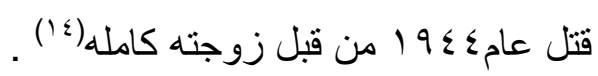

\section{9- نسبيم عودة}

هو نسيم عودة جبر عبداله، ولد في أهوار العمارة عام اسو ا وتأثر بالكثير من المطربين الريفيين في اللواء وتمكن من غناء كل الأطوار منذ صغره، إلا انه تمكن من الانفراد بلون معين يؤديه هو ولم يجيده غيره

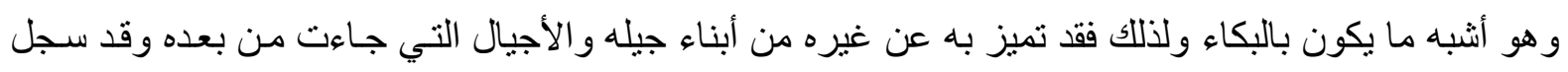

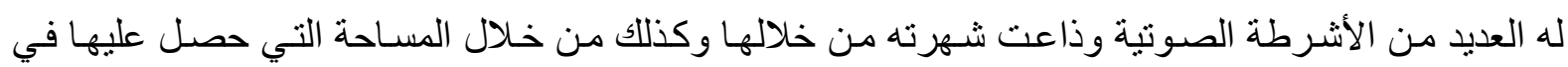

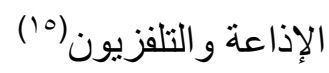


وكانت حفلات الغناء تقام في مختلف مناسبات الأفر اح وقد عرفت مدينـة العمارة عدة ملاهي وكانت أنــهر ها "ملهى الحمراء" التـي أستـمر وجودهـا حتى نهايـة العهد الملكي وكـان يقصدها عدد مـن المطربين و الر اقصات من خارج اللواء('1) وبذلك شكل الغناء جزءاً مهماً من نقافة اللواء و أصبح احد السبل الذي أوصل وهل

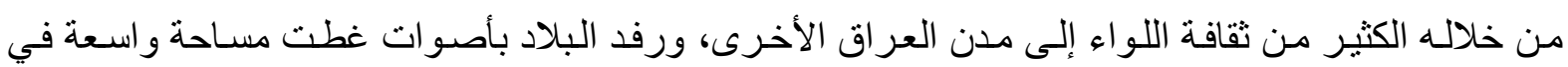
الجو انب الفنية الغنائية العر اقية .

\section{المسبرح والسبـينما في اللهواب}

يعتقد الكثيرون أن المسرح و التمثيل وصل إلينا بعد النهضـة الحديثة التي حصلت بعد الحملة الفرنسية

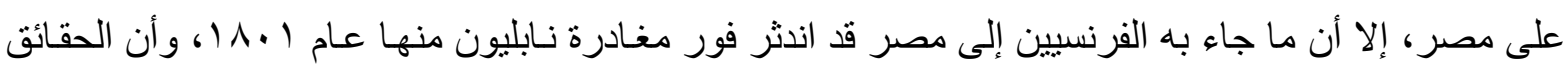
التاريخية تؤكد أن التمثيل عرف في الحضار ات العر اقية القديمة، إما في العصر الحديث فأن وجوده في العراق كان منتشراً قبل أن يعرف في مصر ويسبق ما جلبه الفرنسيون إليها، وذللك من خلال قيام الطائفة الثنيعية في كل المدن العر اقية التي ينتشرون فيها بحركة مسرحية سنوياً وبشكل دوري يقومون خلالها بتأديـة أدوار تمثيلية

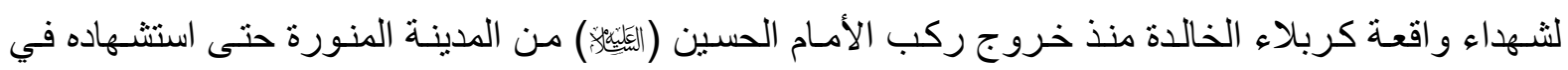
كربلاء في العر اق، يدفعهم لذلك تمسكهم الديني المذهبي وهم بذلك يحرصدون على القيام بتمثيل كل الأدوار بحرفيه عالية تقترب من الحقيقة، حتى تصل أحداثها إلى الجمـاهير ولهذا يعد العراق أسبق البلدان العربيـة في التمثيل(Y') وفي الدولة العثمانية بدأت ممارسة التمثيل نهاية القرن الثامن عشر، إما النشاط المسرحي فقد شهدته في القرن التاسع عشر، وقد تأثر بعض العر اقيين الذين ذهبوا لإسطنبول من أجل الدراسـة أو بحكم العلاقات

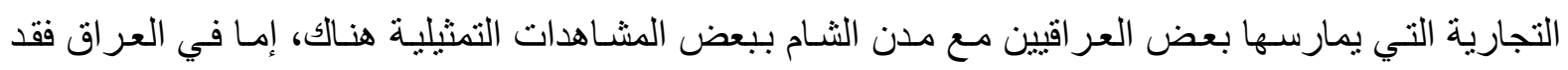
ظهرت أولى الأعمال المسرحية الحديثة في مدينة الموصل عام 1/19 أوكانت مسرحية بعنوان "نبوخذ نصر" ومثلت على مسرح المدرسة "الأكليركية" وهي بذلك تعد من الأعمال الأجنبية، كونها جزءاً من مشروع التبشير المسيحي بعد قيامهم بافتتاح عدد من المدارس لهذا الغرض، وكان المسرح أداة حية في تصوير المشـاهد المراد

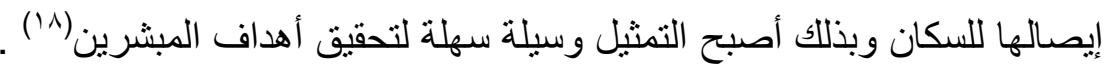

وفي حقيقة الأمر لم يشهد العراق تثكيل أي فرقة للتمثيل حتى بعد انتهاء الحرب العالمية الأولى ولم يعرف المسارح الحديثة، بل عرف شيء بسيط عن التمثيل الهزلي "القره قوز" وهو عبارة عن أدوار بسيطة

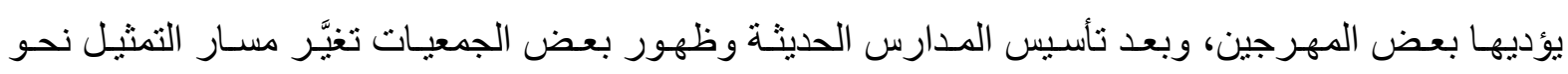
الأفضل، ولذلك يرى البعض أن التمثيل و المسرح ظهر في العراق بعد قيام الحكم الوطني عام ابو أ ويذكر أن

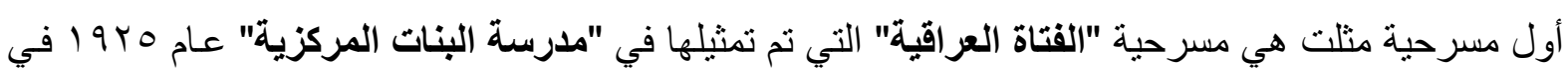
بغداد ثم جاءت بعدها مسرحية "وحيدة" التي طبعت عام • ب9 ا، إما الفرق التمثيلية فكانت أولها "فرقة التمثيل

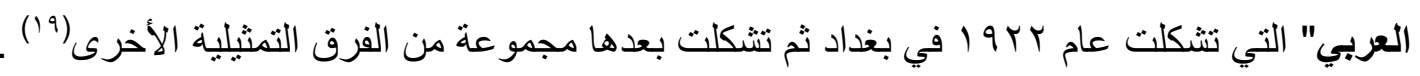

إما في لواء العمارة فقد عرف التمثيل في كافة ضواحي لواء العمارة من خلال قيامهم بتمثيل "واقعة

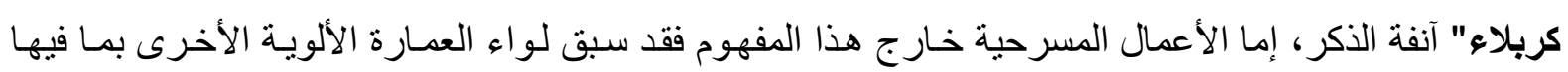


بغداد، فقد شهد اللواء أول عرض مسرحي عام I91V في مدينـة قلعـة صـالح وكان موضوع المسرحية واحداً من أهم الوقائع التاريخية التي يفخر بها العرب إلا وهي قصـة "النعمـان بن المنذر مـع كسرى" وقام بتأديـة

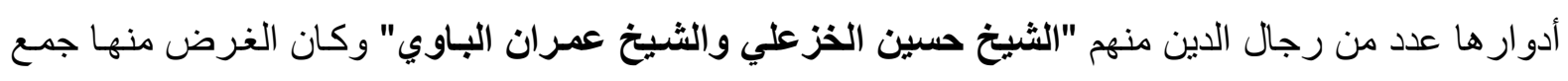
مبلغ من المال لبناء "أول مدرسة ابتدائية" في المدينة وفي عام • ب 9 ا مثلت هذه القصة في بغداد و هذا يؤكد أن

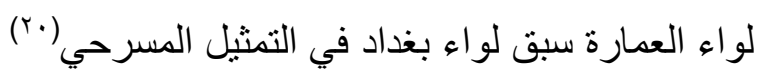

وقد نشطت الحركة المسرحية والفنية في مدينة العمارة وتأسست "جمعيـة أصدقاء الفن" و انضم إليها

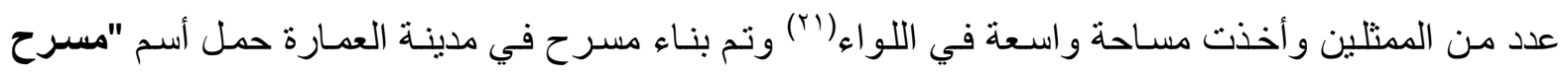

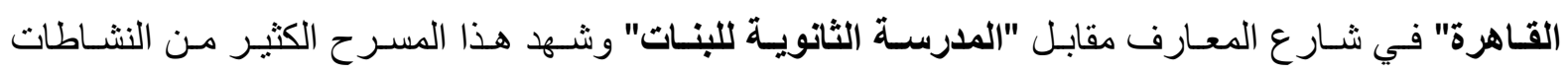

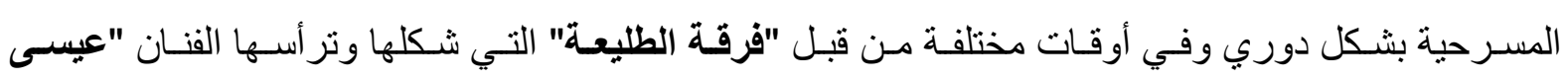
عبدالكريم" ومن أبرز الممثلين المسرحيين في اللواء "سلمان الجوهر، توفيق لازم، سـعيد حسون، عبدالله فيليح، مكي البدري"(rr) وشهدت مدارس اللو اء منذ العشرينات من القرن العشرين، حركة مسرحية واسعة نمت

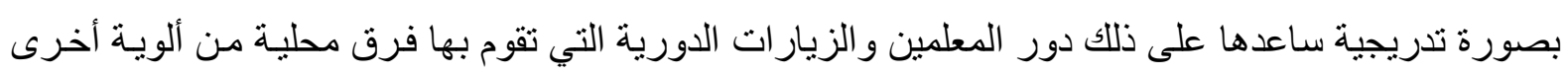

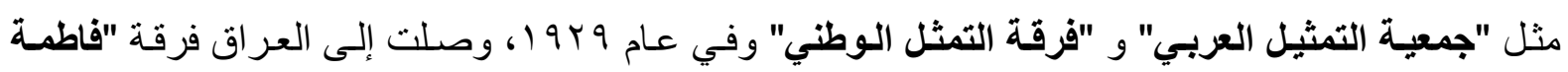

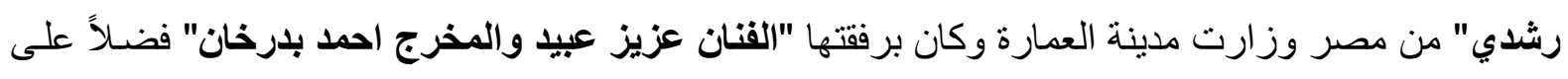

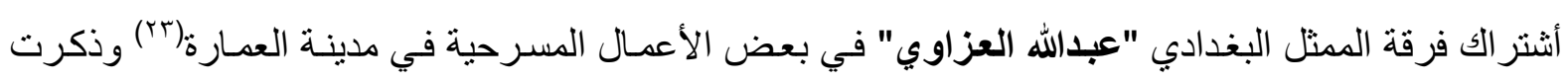

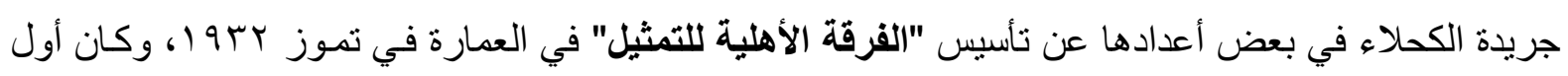

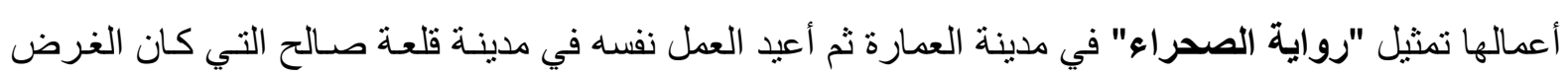

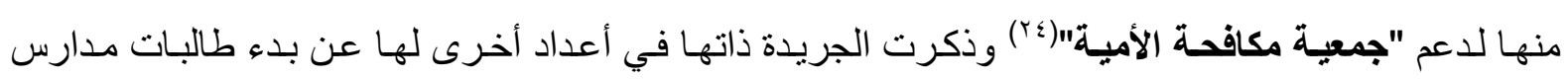
العمارة بالمشاركة في التمثيل منذ عام بrو 1 أضافة إلى مشاركة بر اعم من ريساض الأطفال في تمثيل "روايـة ملكة الحسن والجمال"(ro) و هذه المبادرة بحد ذاتها تعد خطوة كبيرة في هذا المجال، أذ يمكن أن نر اهـا بأنها تحمل الصفة الثمولية لاشتراك غالبية فئات المجتمع العماري في الأقبال على هذا الأمر. ومنذ عام 19 أخذ الفن والتمثيل يتطور في لواء العمارة بصورة كبيرة(r؟r) فقد أشترك عدد من أبناء مدينة العمارة في تمثيل بعض الأدوار في بعض الأفلام العربية، من خلال التمثيل والغناء وفي بداية الأربعينات

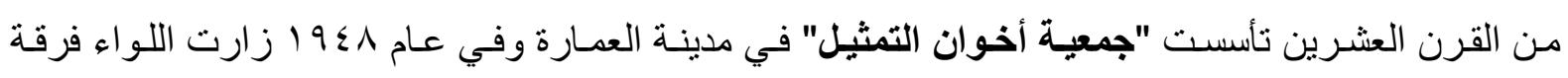
مصرية للتمثيل متكونة من "المخرج المشهور صلاح أبو سيف والممثلين سراج منير وكوكا ويحيى شـاهين وحلمي وقلة وفاخر تحمد فاخر" لتصوير جزء من فلم "مغامرات عنتر وعبلة" وتم ذلك في منطقة "العنتريـة" التابعة لناحية المشرح وقدم أبناء اللواء في تلك المنـاطق مسـاهمة مجانيـة للفرقة المصرية من خـلال اشتر اكهم بالتصوير بهذا الفلم مستخدمين خيولهم وملابسهم التقليدية "كومبارس" و استخدامهم أر اضي اللو اء دون مقابل

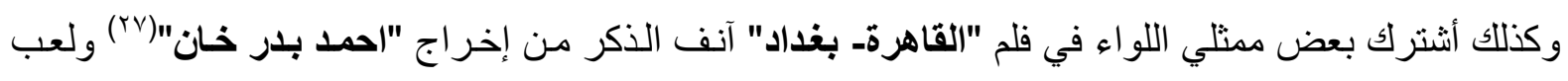

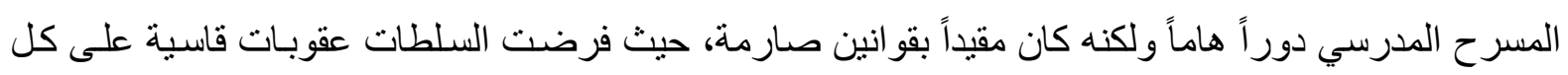


طالب يقوم بتأدية أدوار تمثيلية في المسر ح الأهلي الذي كان جميع التمرينـات الخاصـة بـه تقام في بعض بيوت العمارة:(r)

فقد ذكرت جريدة الكحلاء العماريـة في عدة أعداد منهـا والصحف العر اقيـة الأخرى بعض الروايات العالمية و المحلية التي مثلت في مختلف مناطق اللواء ومنها: "أنـا الجندي، مـأتم الأعراس، الأقدار، الأميرة

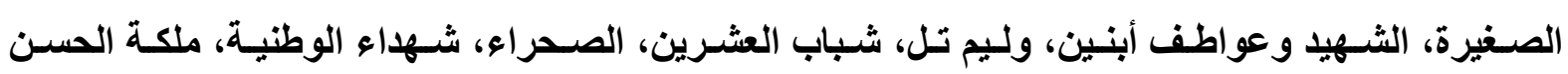
والجمال، عنتر العبسي، الكثاف، في سبي التابع، غرام في الريف، بؤس الفـلاح العراقي، الصدق والوفـاء، شـهامة العرب، هاملت أمير الدنمارك، مستقبل العرب، فتح مصر، المروءة والوفاء، الزوواج في الريـف، مصرع الظالمين، قاتل أخيه، مجنون ليلى" و غير هـا الكثير وظهر عدد من كتاب الروايـات في مدينـة العمارة

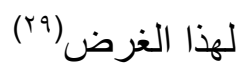

و هناك رافد ثقافي مهم أخذ مساحة واسعة في المجتمع العماري، إلا وهو "دور العرض السينمائي"(·)

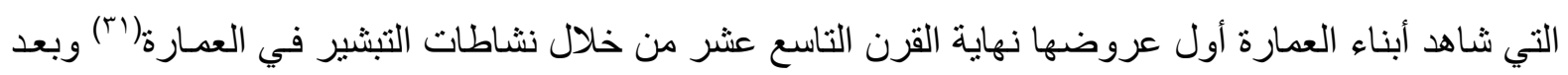

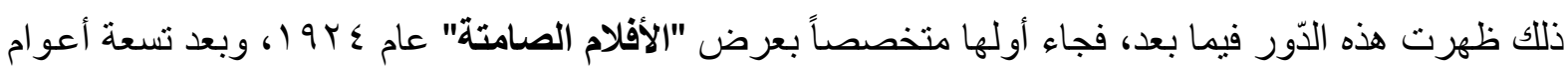
تم أنشاء "سينما النجاح" ثم جاءت بعدها "سينما الحمراء" في أربعينـات القرن العشرين، وفي الخمسينات من القرن نفسه أنشئت "سينما رينجيت" التي غير أسمها فيمـا بعد إلى "سينما الأمير" وجميعها تعود لشخصيات عمارية وكانت محصورة في مدينة العمارة فقط، إما الجانب الحكومي فقد انشأ "سينما غازي" في مدينة العمارة

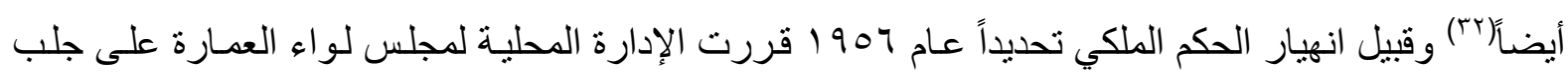
"ثلاث سينمات صغيرة" مع كل مـا يتعلق بها وان يتم تقديمها لثلاثة أقضية هي: "العمارة، قلعة صـالح، علي

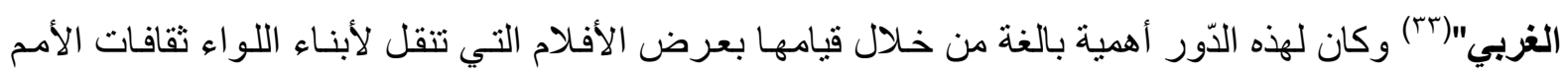

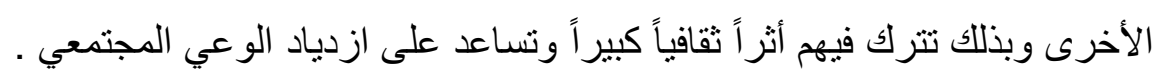

فضلاً عن ذلك تقام في مدينة العمارة جملة من الأنشطة الفنية بر عايـة الدولة ومنها المعارض السنوية

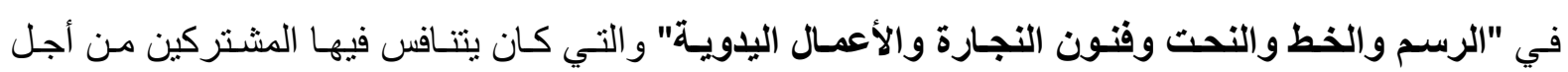

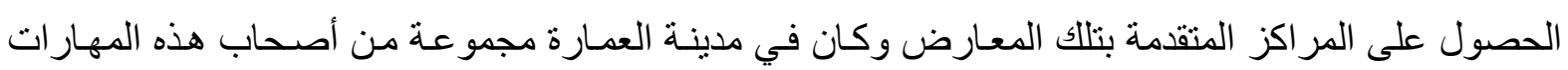

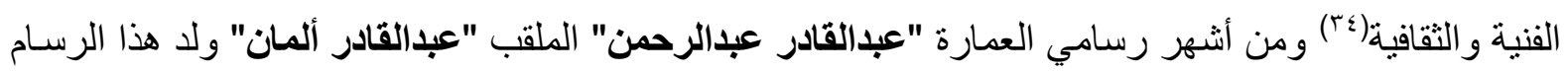

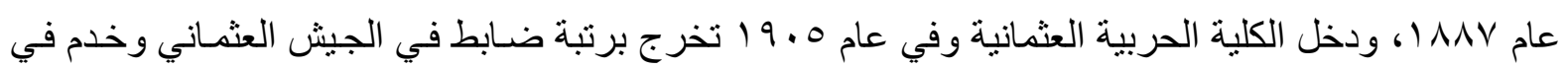
صفوف الجيش في مدينة قلعة صالح وبعد هزيمة الدولة العثمانية في الحرب العالمية الأولى، عمل معلمـاً متنقلاً ما بين العمارة وقلعة صالح وأستمر في ذللك قرابـة ربع قرن وبعد عـام • ـ9 1، أحيل على التقاعد وفي العام

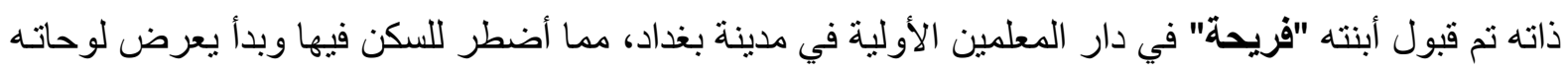

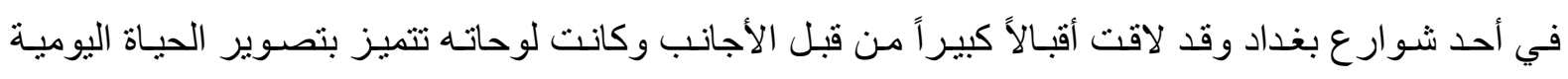

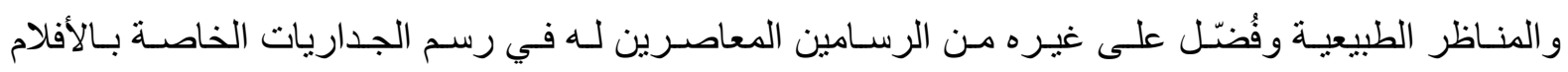
المعروضـة في بعض السينمات وقـال عنـه الناقد العربـي "جبرا أبراهيم جبرا" التـالي: "خلف لنـا عدداً مـن 
المشاهد الفسيحة لبغداد وغيرها تتسم بأتساع الأفق وكثرة التفاصيل الصغيرة ورغم أن أسلوبه لا يتصل أبـاً بأسـاليب الرسم الشـائعة في العـالم المتقدم آنئذ، فإن لنـا أن نعتبره عن حق أبـا الرسم المعاصر في العراق" وتعلم الرسم على يديه الكثير من رسامي العراق ومنهم "عاصم حافظ، تحمد سليم، عحم صالح زكي" ومن الجدير بالذكر أن الفنان العر اقي "فائق حسن" بدأ مقلداً للرسام العماري عبد القادر، ويحتفظ "المتحف الوطني العراقي

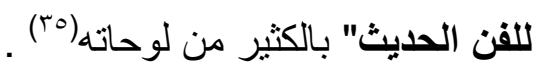

أضـافة إلى وجود بعض الفنون الفلكلوريـة النابعـة من ثقافـة فطريـة في اللو اءو ومن أهمها "الصياغة والنقش على المعادن الثمينة" التي تميز بها الصابئة وكان من اشهرهم "عنيسي الفياض" الذي أصبح الصـائغ

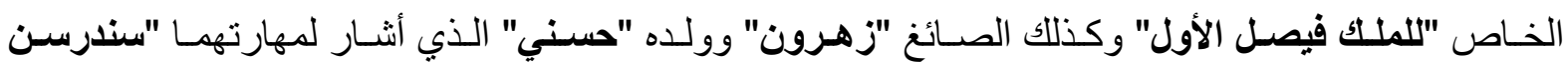
باثـا"(זr) وقد أصبح "زهرون" مر افقاً "للملك فيصل الثاني" أثناء سفره إلى فرنسـا وقد حوى "متحف اللوفر"

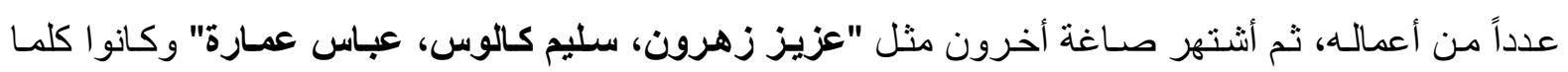

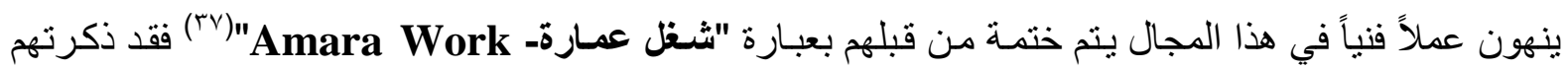
"مدام ديولافوا" بقولها: "يكاد عمل وحرفة هذه الطائفة ينحصران في صياغة الحلي الفضية وفي مصنوعات

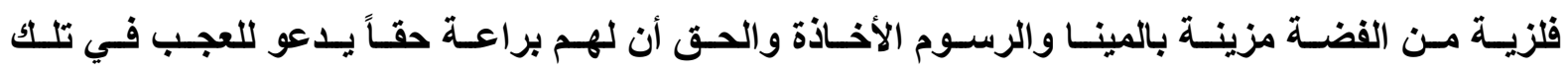
المصنوعات"(^^) وقد برع من بينهم وحصل على شهرة عالمية "عباس عمارة" وسنتناول حياته بإيجاز . هو "عباس عمارة مرّان" و الد الثناعرة "لميعة عباس" وخال الثناعر "عبدالرزاق عبدالواحد" فنان في خط اللغة العربية واللغة الإنجليزية ونقاش للذهب و الفضة ومن مثققي مدينة العمارة التي ولا فيها عام 19 (19، وتلقى تعليمه الأولي على يد خاله "زهرون" ودرس الديانة واللغة المندائيسة على يد خالة الأخر "جودة" ودخل

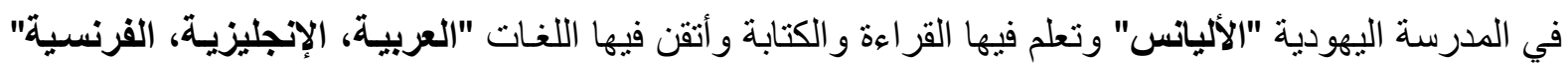
وتمكن من أتقان "اللغة الإيطالية" فيما بعد ومثل العر اق عالمياً في الكثير من المناسبات و المهرجات والمعارض

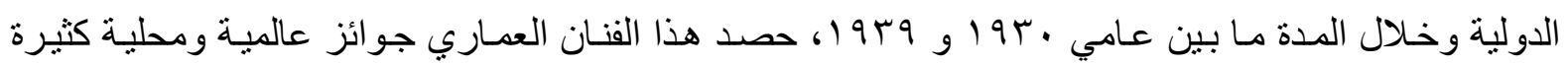

1 - "جائزة المعرض الزراعي الصناعي ببغداد" (العراق) .

r- "دبلوم من معرض باري الدولي" ( اسو ا ) .

r- "الميدالية الذهبية من المعرض الزراعي الصناعي في الإسكندرية" (مصر- سبو () . . ع - "دبلوم من معرض نابولي الدولي" (إيطاليا) .

0ـ "جائزة من معرض طرابلس الغرب" (لييا- مستعمرة إيطالية) .

7- "دبلوم من معرض روما الدولي" (إيطاليا) .

V- "ميدالية أحمد باي- معرض تونس الدولي" (تونس- مستعمرة فرنسية) . 
A- "وسام الثرف الفرنسي(الليجون دونور)" (معرض باريس العالمي- Vra ( ).

9 - "المعرض العالمي" (نيويورك- و أفتتح هذا المعرض الرئيس الأمريكي روزفلت- 9ب9 1 ) .

وكان من أقرب أصدقائه "روفائيل بطي" و "إيليا أبو ماضـي" صـاحب ديونـه "الخمائلس" الذي أحتوى

على عدد من القصائد و عند طباعته كانت جميع عنـاوين قصـائده بخط "عبـاس عمـارة" و عندما كان في شمال أفريقيا قام بنقش بيت من الثـعر على خـاتم فضي قام بصياغته "عبدالواحد" والد الثـاعر "عبدالرزاق" الذي وعي أصبح الأقبال عليه بشكل كبير وتم عمل المئات منها وجميعها نفذت حتى أصبح اقتناء هذا الخـاتم رمزاً للشباب الثائر الذي يناهض الاحتلال الأوربي في مناطق شمال أفريقيا وقامت سلطات الاحتلال بمنع عمل هذا الخـاتم

لأنه كان احد الدوافع الثورية للثباب العربي لرفض الوجود الأجنبي على الأراضي العربية، وكان البيت(•؛):

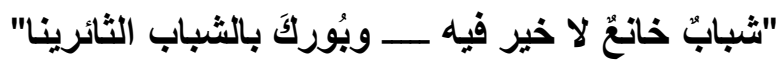

ومن أشهر النقاثشين على "الحجر والخشب" في لواء العمارة هو "أحمد محمود أغا أبراهيم الجدّة" الذي ولد في مدينة الحلة عام 1901 و انتقلت أسرته إلى مدينة العدارة للعدل والتجـارة، وقد درس منذ طفولته في كتاتيب العمارة واهم من علمه القراءة والكتابة وتحفيظ القرآن الكريم "سليم أفندي المفتي، احمد الأنصساري، حبيب العاملي، عبدالحسين الأصفهاني" وحضر مجالس "عبدالمطلب الهاشـي" وقد أثنتهر بـالنقش بطريقة هندسية وحرفية عالية ولم ينافسه أحد في هذا المجال وترك بصمات أثناره في أغلب القصور و البيوت العماريـة

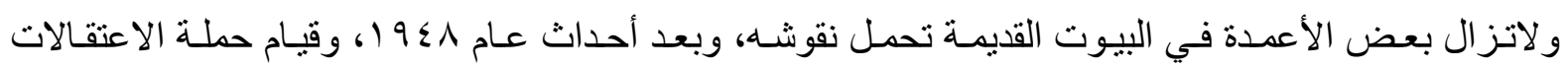
الثعو اء التي شنتها السلطة الملكية تم اعتقال ولده البكر من دار المعلمين العالية و غييته بعد ذلك في سجن "نقرة السـلمان" ترك الجدّة العدـارة وهـاجر إلى الكويت وتمكن من العمل مـع أمير الكويت "الثـيخ أحمد الجـابر الصباح" وتمكن من هندسة وزخرفة قصور الأمر اء فيها وكانت أقامته في الكويت مـا يقارب ربع قرن ثم عـاد إلى العمارة:(1)

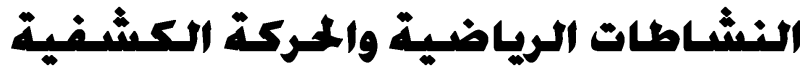

تعد الحركة الرياضية في العراق في العهد العثماني شبه معدمة وغير موجودة ولم يكن للدولة أي دور

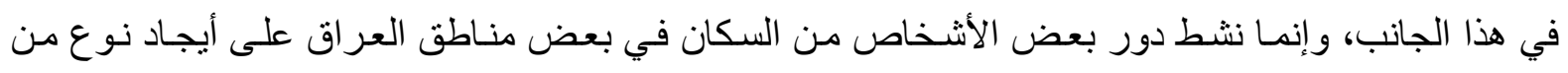
الألعاب الثعبية ووجدوا لها ملاعب يطلق عليها "الزور خانة" وكان هؤلاء يمارسون فيها بعض الألعاب البدنية المحدودة ومنها "المصارعة" التي تقام لها بطو لات بشكل دوري ولكنها تفتقر إلى أبسط القو انين و الضو ابط، فعلى سبيل المثال كلما كان المنتمي إليها أقدم من غيره كان يحصد المراتب الأولى في كل نز ال حتى لو خسر النزال مع شخص حديث الانتماء لهذه اللعبة وبذلك لم يحصل أي تقدم في فنون هذه الألعاب(؟ء) .

وفي عهد الاحتلال البريطاني بدأت النشاطات الرياضية تأخذ منحى أخر من خـلال المدارس وخاصـة بعد حصول نوع من الاتصـال بين المحتلين وبعض الأفراد من السكان الذين لديهم رغبـة بالتوجها الرياضي و على الر غم من ميول الكثير نحو ها، إلا إنها لم تكن منظمـة وتعمها الفوضى ولم يفكر أحد بمـا يمكن أن ينتج 
عنها ولم تعرف فو ائدها بـل كانت الرياضـة تعد عبـارة عن واحدة من وسـائل التسلية(َّ) و عندما انتقلت مهام المعارف إلى شخصيات عر اقية حصلت الرياضة على نوع من الاهتمـام واستحداث "مديريـة الرياضـة البلنية

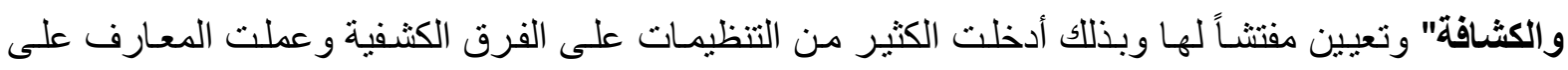
تخصيص جزءٍ مهم من الدعاية لها، حتى تمكنت من إيصـالها إلى فئة الثباب بطريقة محببة وتأثر بذلك نسبة

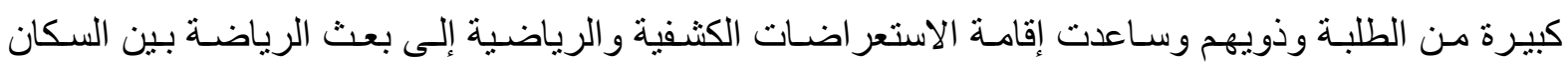
بصورة عامة، وبعد ألتحاق "الأمير غازي" في صفوف الكثـافة الذي لقب فيما بعد "بحامي الكشـافة الأعظم" بلى فضلاً عن إقامة الحفلات الرياضية السنوية وحضور "الملك فيصل" وبعض الشخصيات الحكوميـة فيها سـاعد على تثـيع الحركة الرياضية في العراق، وفي عـام • ب9 ا حرصت وزارة المعـارف على الاهتمام بفنون الرياضـة بأنو اعهـا كافـة عندما قامت بوضـع عناصـر مختصـة بها ووضـع بـر امج خاصـة تقوم على الدراسـة

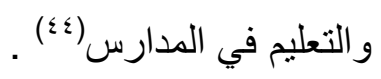

وفي عام هبو ا قامت "مديرية التربية البدنية والتدريب العكري" على توحيد الحركة الرياضية في العراق و عملت على تقسيم العام الدراسي لعدة أقسام وخصصت لكل قسم منهـا مجمو عـة من الألعاب الرياضية

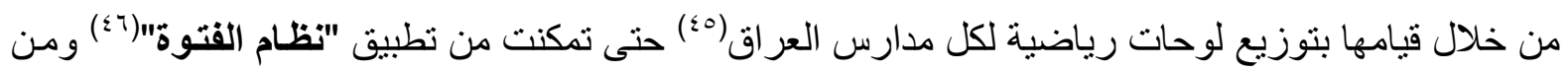
الهم الألعاب الرياضية التي أصبحت معروفة بالعراق بشكل منظم "الجمناستك، كرة القدم، كرة السلة، كرة الطائرة، الهوكي" بالإضـافة إلى لعبة "كرة المنضدة" التي دخلت أولاً في نـادي الطلبة وتم تخصيص حصنتين

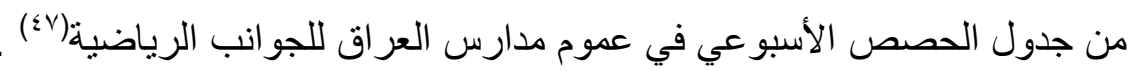

إما في لو اء العمارة فقد انتعشت الحركة الرياضية منذ بدايـة الحكم الوطني للعر اق وكان للنشـاطات الكثفية سمة بارزة وخاصة بعد زيـارة الوفد الكثفي الألماني الذي تمت استضـافته في مدينـة قلعـة صـالح كمـا ذكرت هذا الأمر جريدة الكحلاء في أحد أعدادها وذكرت بأن ستة منهم وصلوا القلعة في الثامن عشر من مايس

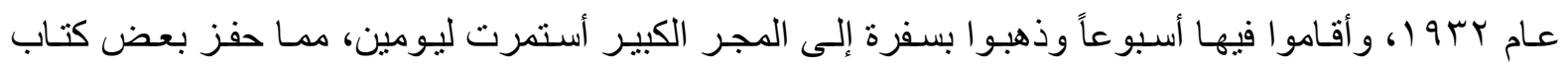
العمارة من نشر مقالات تطالب الحكومة بإيفاد الكثافة العر اقيين إلى الخارج ومن ضمن من كتب هكذا مقالات المعلم "غضبان رومي الناشئ" وقد ذكرت جريدة الكحلاء بأنها خصصت حقلاً للأنشطة الرياضية في اللواء وذكرت بـأن الرياضـة لم تقتصر على طلاب المدارس فقط و إنمـا شكل أفر اد شرطة العمـارة فرقاً لكرة القدم وفرقاً للقوة النهرية للزوارق الخاصـة بالسباقات النهريـة وكانت الصحافة في العمـارة الصـوت الرياضـي الذي أستقطب السكان لها(^§) وكانت الفعاليات الرياضية التي تقام في مدينة العمارة تشترك فيها جميع مناطق اللواء وفق دورات محددة من كل عام وتتوج تللك الفعاليات بكرنفال رياضـي كبير يجتمع فيه الكثير من الثخصيات

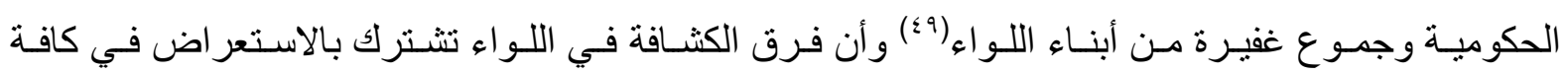
المناسبات وقد حصل ذلك عندما جاء الملك فيصل وولاه غازي من أجل الراحة و الاستجمام عام ع به أو وكانت تللك الفعاليات في المجر الكبير، وفيما بعد تشكلت في العمارة "لجنة الألعاب الرياضية العامسة" وكانت تضم في وني عضـويتها عدد مـن المعلمين و انبتقت بعد ذلك تأسيس بعض النوادي الرياضية مثل: "نـادي العـارة، نـادي 
الكحلاء، نـادي الطلاب، نـادي المعلمين"، ومن الأحداث الكثـفية المهمة فقد أشترك مئتان وخمسـة وأربعون

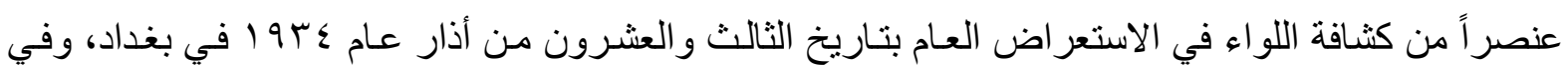

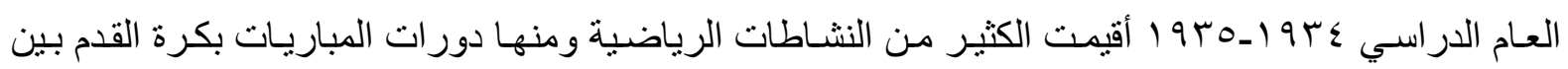
ألوية العراق حيث لعبت فرق العمارة مع فرق الكوت وكان الفوز من نصيب لواء العمارة(·) .

وذكرت جريدة الكحلاء أن الحركة الرياضية في اللواء أصبحت نشطة خلال عام هبه 19 حيث أقيت

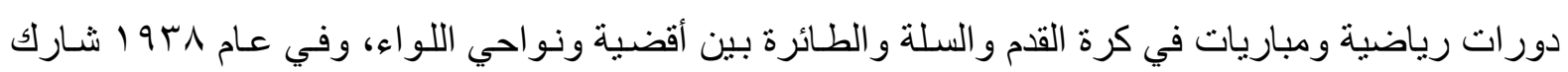

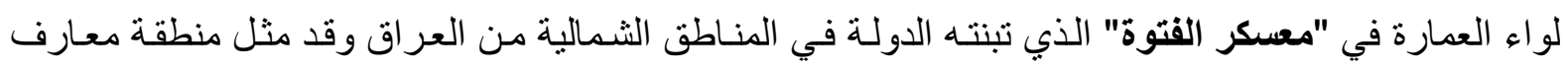

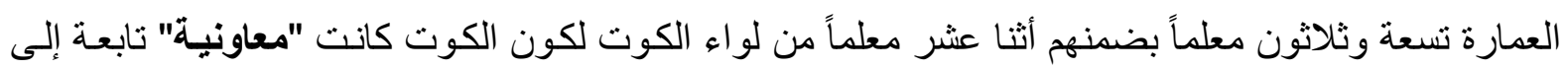
"منطقة معارف العمارة"(0)

وقام البريطانيين بأنشاء ملعب متكامل في مدينة العمارة أطلق عليه "ملعب الماجدية" نسبة للمحلة التي وجد فيها وكان يحتوي على كافة مستلزمات الألعاب الرياضية واحتوى على مدرجات حديثة ومقصورة كبيرة

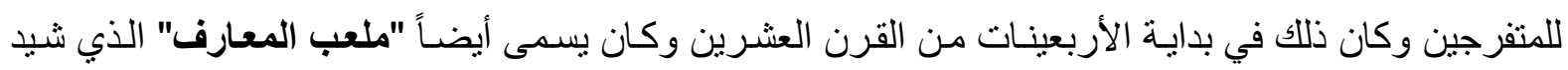

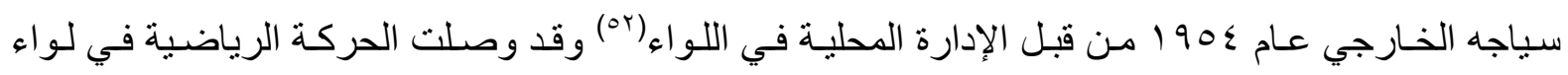

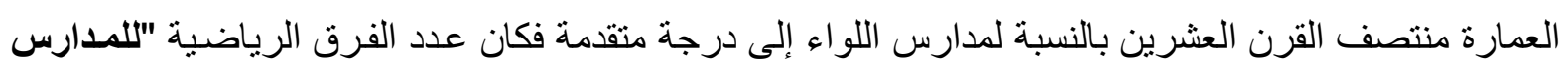

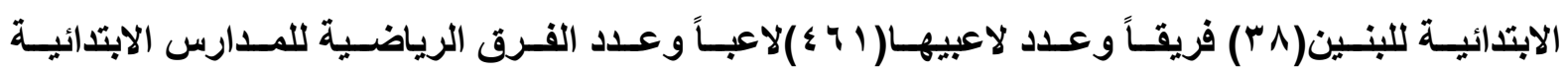

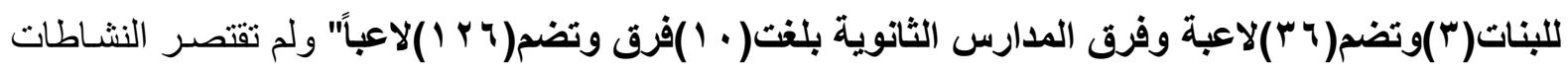
الرياضية على المستوى الحكومي فقط، وإنما تشكلت مجموعة من الفرق الرياضية الأهلية التي أستمرت حتى وفى نهاية الحكم الملكي ومنها: "فريق القوة النهرية، فريق العوادي الأهلي، فريق الطليعة، فريق المصارعة، فريق فيصل الرياضي"(or)

وأخذت الحركة الرياضية في اللواء بالتقدم والازدهار وحصل بعض الرياضيين فيها على شهرة واسعة

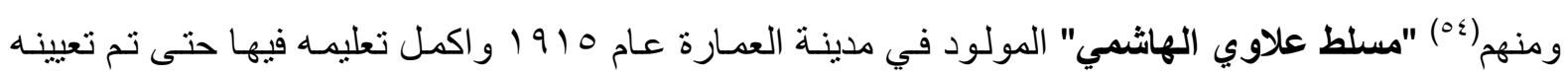
معلماً في مدارسها ومارس العديد من الألعاب الرياضية فكان "بطل العراق بالمصـارعة عام هـ هو ا" و "بطل

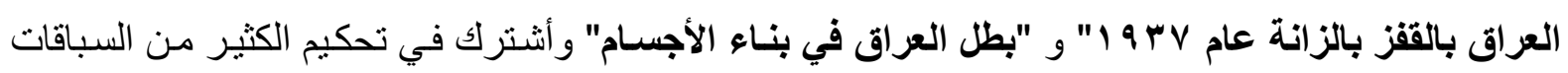

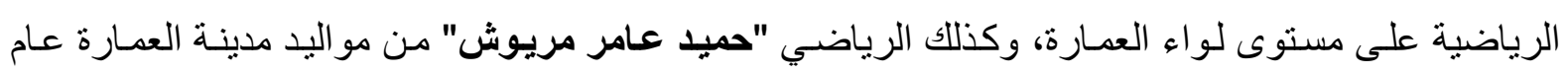

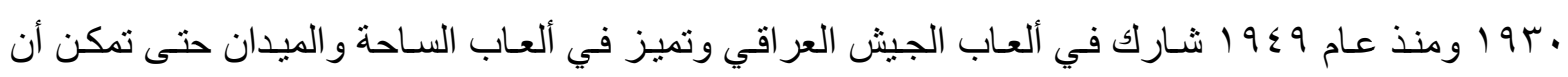
يصبح "بطل الجيش العراقي في لعبتي( · · ؛م) و( · . دم)" وحصد الكثير من الكؤوس التي أستلم بعضـاً منها

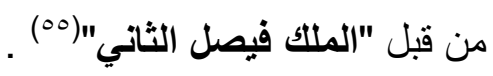

وبذلك شكلت جميع النشاطات الرياضية والكثفية وسيلة مهمة من وسائل تثقيف وتهذيب أبنـا مجتمع لو اء العمارة، من خلال ممارستهم لها جعلتهم يشكلون جزءءً ناضجاً من المجتمع وبالتـالي سـاعدت على تقويـة ورصـانة المجتمع العماري، فضـلاً عن منحهم الثقة بـالنفس ورفع مستوى طموحستهم و اطلاعهم على ثقافات 
أخرى سواءٍ على المستوى المحلي أو الإقليمي والعـالمي، بالإضـافة إلى دور هـا في نشـر ثقافة صـحية عامـة

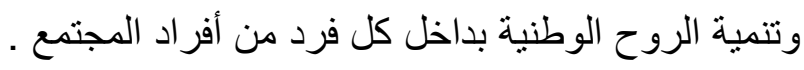

الماتمة

أن الجو انب الفنية و الثقافية والرياضية المتمثلة في الغناء و المسرح و التمثيل وبعض الفنون و الأنشطة الرياضية، كان لها دور مهم في أنعان الحركة التقافية في لواء العمارة وساعدت على التقدم والرقي في اللواء ورفدت العر اق في الكثير من الثخصيات التي شغلت حيز ا في الفضاء الثقافي العر اقي، من خـلال مـا قدم اللواء من مطربين ذاع صيتهم من خلال الإذاعة العر اقيـة أو من خـلال شخصيات المسرح و التمثيل التي رفعت اسم العر اق من خلال الاشتر اك في العديد من الأعمال الفنية العربية ومساهماتهم الفاعلة، فضـلاً على مـا قدمته دور العرض السينمائي التي عملت على رفد الفرد العماري بثقافات أخرى، من خـلال مـا يعرض فيها من أفلام عالمية وما قدمه اللواء من شخصيات تميزت بفن النقش من الذين عرفوا في المحافل الدولية ووصلت أعمالهم

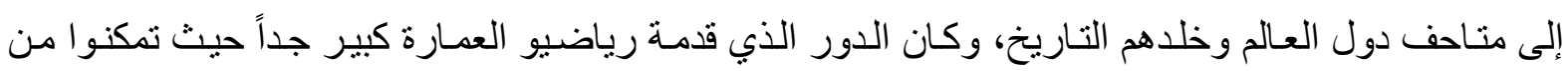
خوض مختلف الألعاب و السباقات و أصبحوا أبطال على مستوى العر اق، أن جميع هذه الأنشطة كان لها دور واضح وجلي في رفد الحركة الثقافية في لواء العمارة وجعل الحركة تصل إلى مستويات متقدمة .

\section{الهوامش}

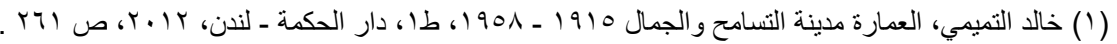

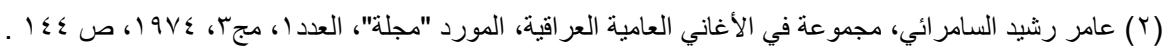

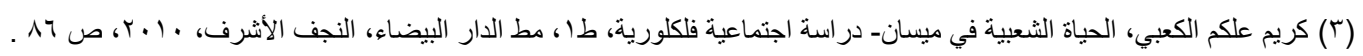

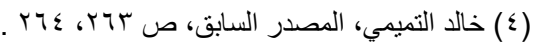

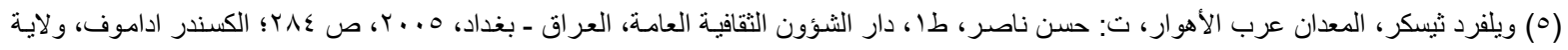

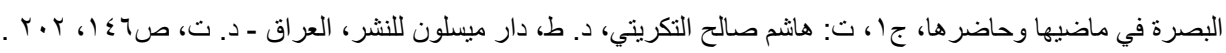

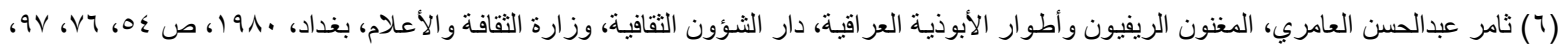

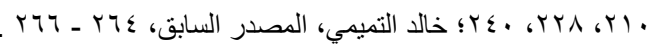

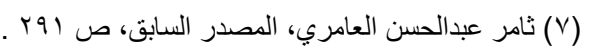

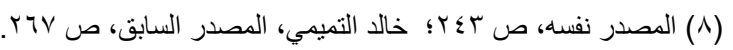

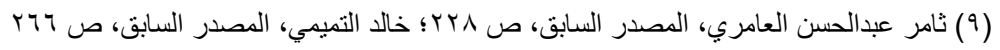

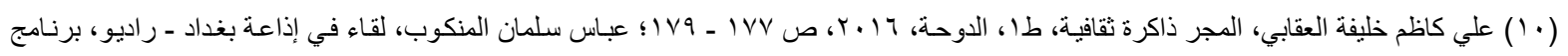

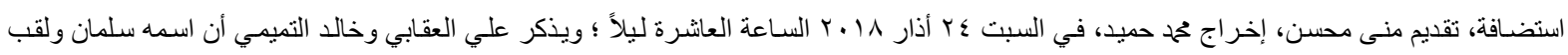

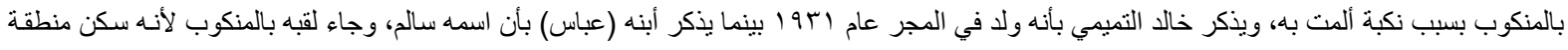

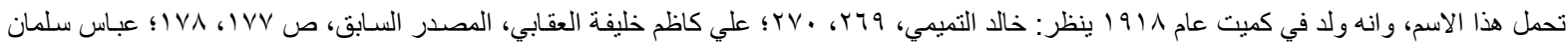

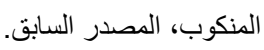

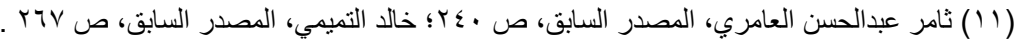

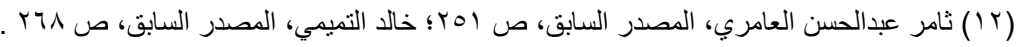

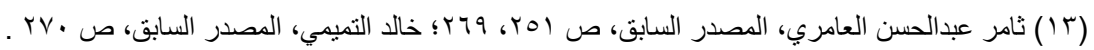

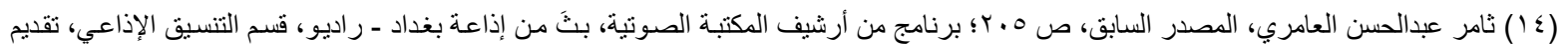

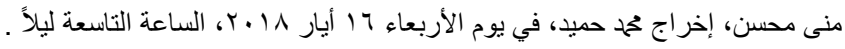

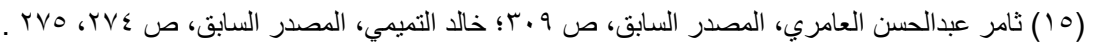

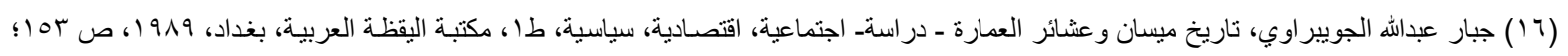




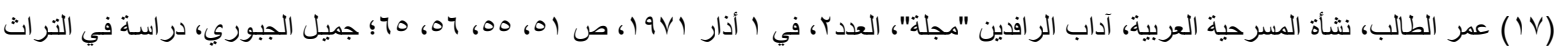

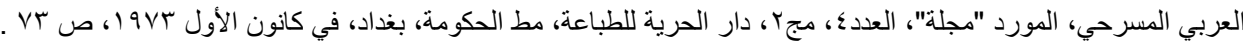

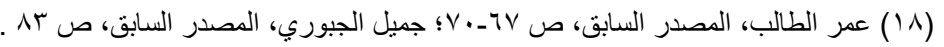

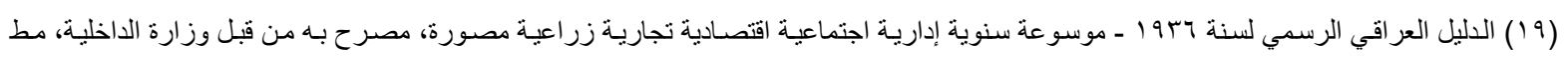

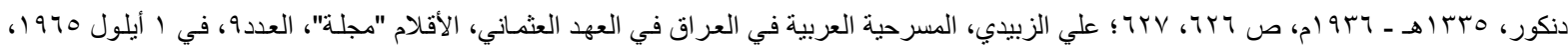
. Or ، ص ص

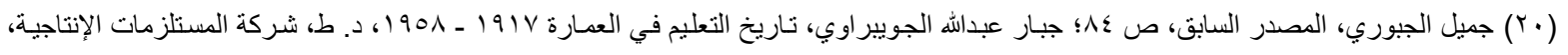

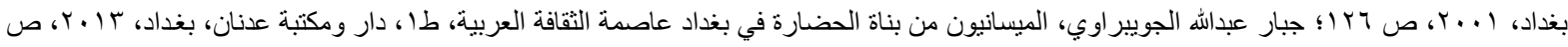

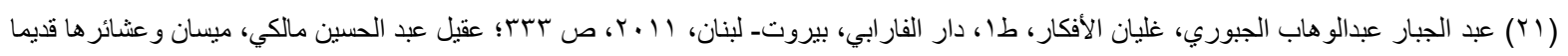

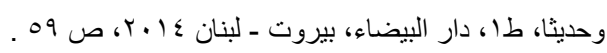

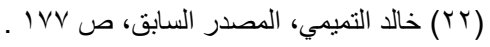

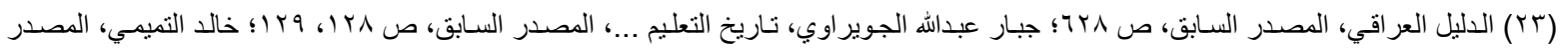

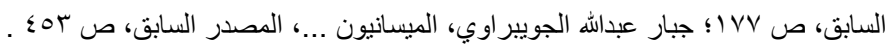

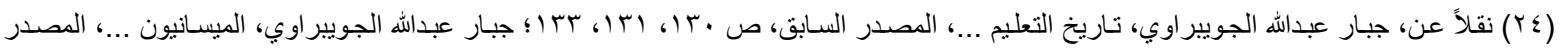

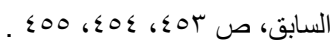

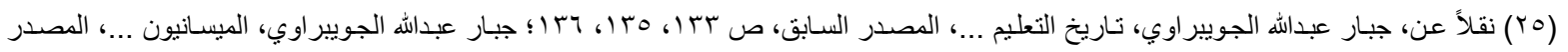
السابق، ص 00؛ ـ

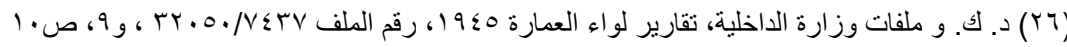

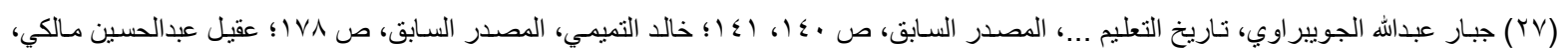

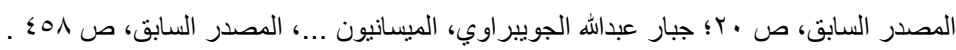

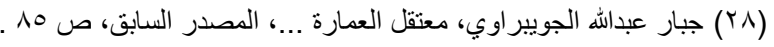

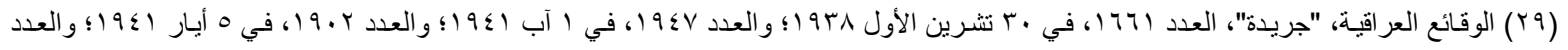

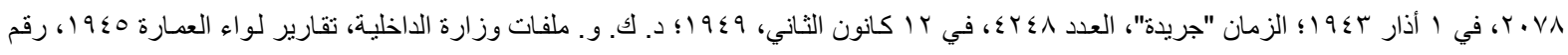

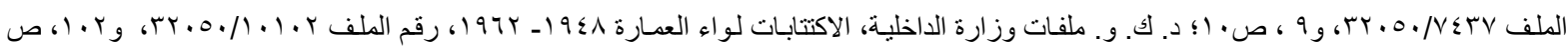

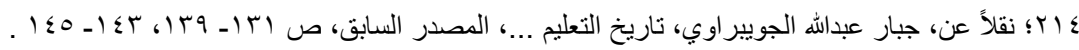

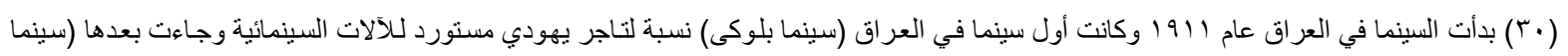

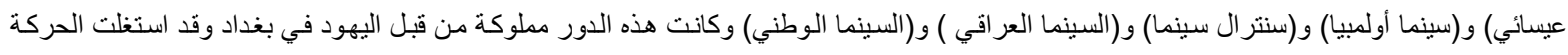

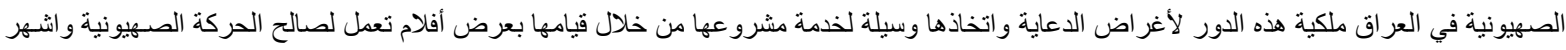

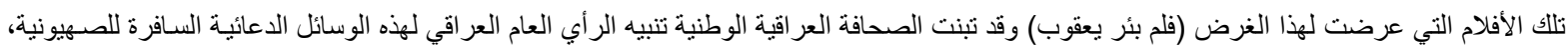

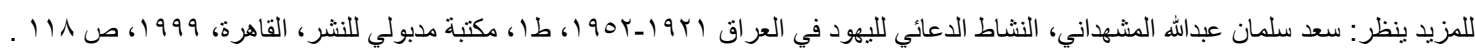

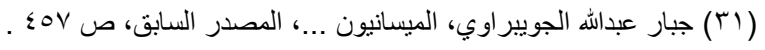

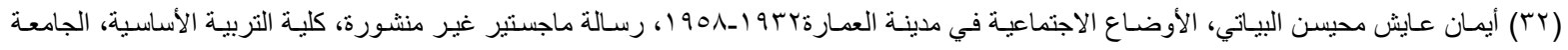

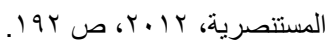

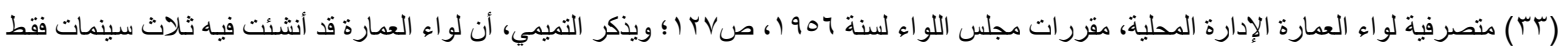

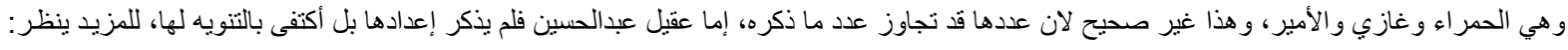

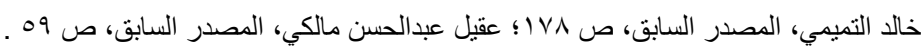

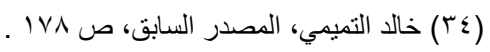

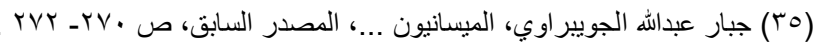
( آس) سندرسن باشا: هو (هاري سندرسن) طبيب بريطاني يعد من اشهر الشخصيات البريطانية التي عملت في العراق أثناء العهد الملكي وبحكم عمله طبيباً

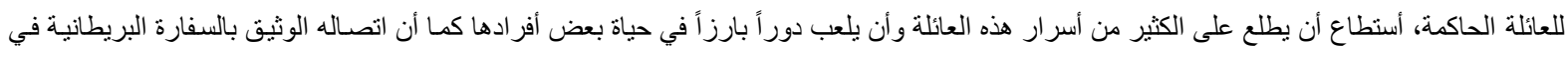

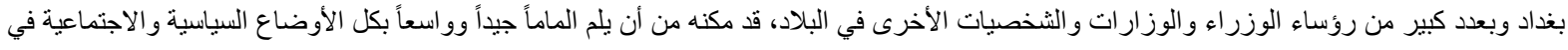

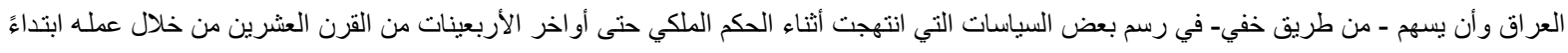

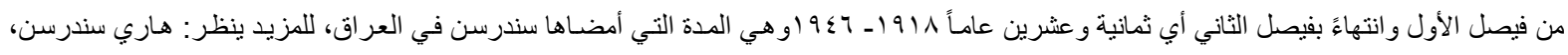




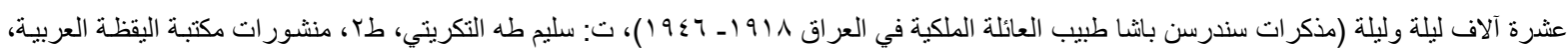

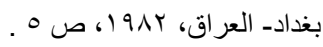

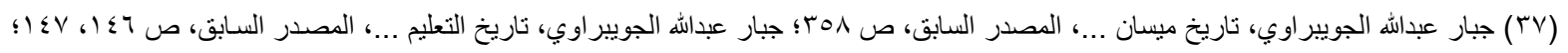

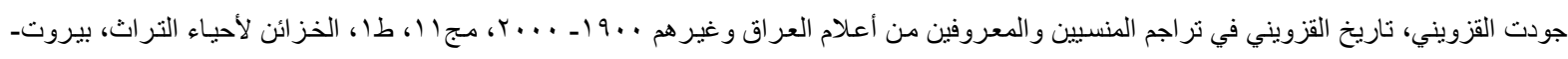

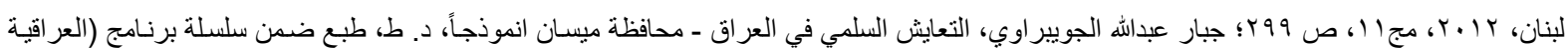

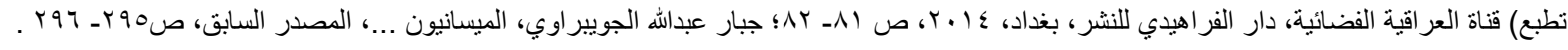

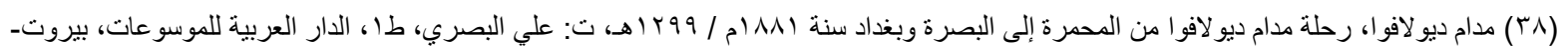

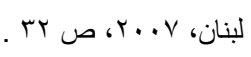

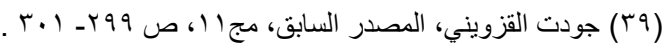

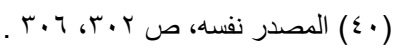

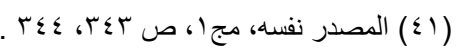

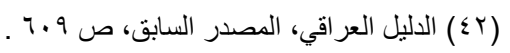

(

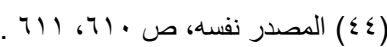

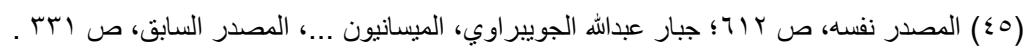

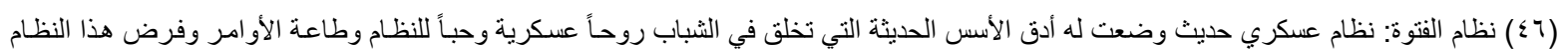

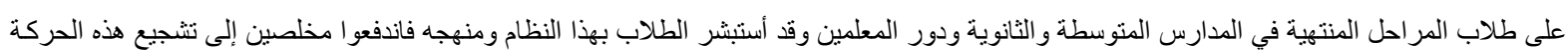

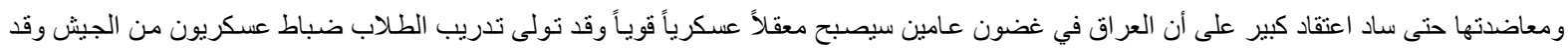

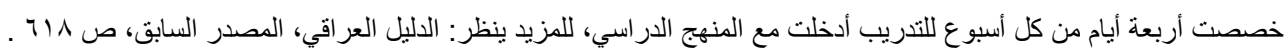

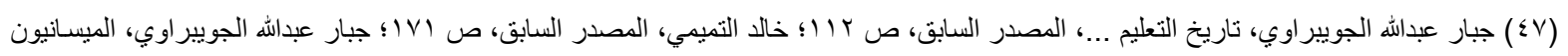

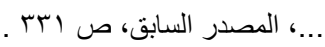

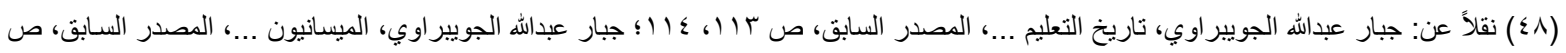

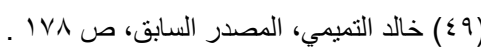

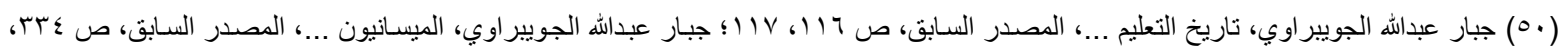
rro

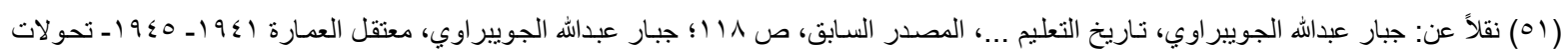

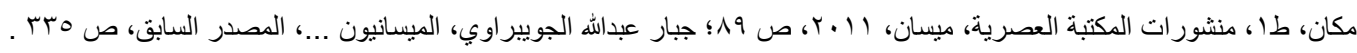

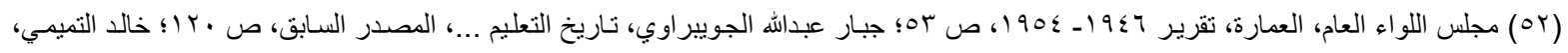

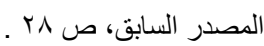

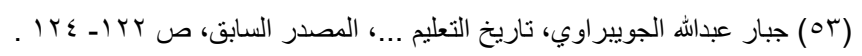

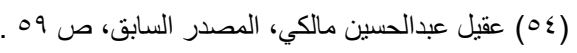

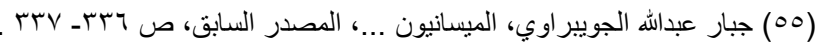

